\title{
Drilling Tool Geometry Effects on the Hole Quality of Glare
}

\author{
Thirukumaran M., Winowlin Jappes J. T., Siva I.
}

\begin{abstract}
Recently machining of hybrid stacking materials are much interested and challenging in manufacturing domains. Mostly, drill hole quality depends the machining parameters and type of cutting tool. This work investigates the experimental study for effects of drill bit geometry on hole quality of glass laminate aluminum reinforced epoxy (GLARE). GLARE have manufactured by alternative stacking of aluminum (AA7475) and glass fiber (E-glass)/epoxy composite through compression molding machine. Machining of GLARE by using of Computer numerical controller. Hole quality were studied with the aid of optical microscopic. Results show that a drill tip geometry to promote the reduction of delamination and structural damage. Superior hole quality is achieved with 2 fluted drill bit than 3 fluted drill bit.
\end{abstract}

Keywords : CNC drilling, delamination, hole quality, GLARE.

\section{INTRODUCTION}

$\mathrm{R}$ aviation structural applications. In aero-structural designs, materials joining played a serious role in deciding the over-all strength. By the way, drilling is one of the machining processes used in aerospace industries to join different entities. Hybrid materials stacks (fiber-metal laminates) required a number of drills during assembly (bolting or riveting). Drilling is the primary and simplest process involved here. There are many key drilling parameters influencing the hole quality. Drill bit material, drilling method, drill bit geometry are some of them. Among various drilling process Conventional drilling (CD), Grinding drilling (GD), Vibration-assisted twist drilling (VATD) and High speed drilling (HSD) are some often referred processes. Drill bit can be found in twist drill bit, brad point drill bit, slot drill bit, straight-flute drill bit, Core drill bit like geometry based on the necessary of the respective process [1].

Challenges occurred during the drilling of the FML are mainly controlled by feed rate and cutting speed. The increased feed rate in drilling of Carbon fiber Reinforced

Revised Manuscript Received on December 29, 2019.

* Correspondence Author

Thirukumaran M, Centre for Composite Materials, Department of Mechanical Engineering, Kalasalingam Academy of Research \& Education, Virudhunagar, Tamilnadu, India Email: mkthirukumaran@gmail.com

Winowlin Jappes J T*, Centre for Composite Materials, Department of Mechanical Engineering, Kalasalingam Academy of Research \& Education, Virudhunagar, Tamilnadu, India Email: winowlin@klu.ac.in

Siva I, Centre for Composite Materials, Department of Mechanical Engineering, Kalasalingam Academy of Research \& Education, Virudhunagar, Tamilnadu, India Email: isiva@klu.ac.in
Polymer Composites (CFRP) reduced effective clearance angle of the drill, and there by creates rubbing against the CFRP/Al stack resulting in higher thrust and torque [2]. Lower the speed and feed produces continuous chip, which normally produces high surface roughness. To break the chip into segments one possible solution would be to increase depth of cut. Chip breakability occur of the increase in cross sectional area of chip (stiffness of chip increase). For the CFRP, the circularity is found to be around $6 \mu \mathrm{m}$ at low feed rates, when the feed is increased the circularity be increases [3].

During drilling, the cutting edge directly contacts the specimen without the presence of the stagnation zone. This leads to a rapid dulling of the cutting edge. Such an issues includes fiber breakout, fiber pullout, and most importantly the "delamination", where the drill flute pulls out the first layers of the composite material. When drilling more numbers of holes on a panel, due to bur and temperature raise in the tool, severe edge rounding may resulted [4, 5].

A novel approach is check the hole quality with cutting edge rounding (CER) on carbon fiber/epoxy composite. The cutting edge rounding influence the both entry and exit delamination of the hole. From the CER to identify the magnitude as well as hole quality were characterize the evenly and smoothly drilling on CFPR composite [6]. An additional approach is effect of chip shape and breakability were also influence the quality of the hole on Al/CFRP/Ti. While the not as much of spindle speed and diameter of the drill is maintain very less cross sectional area of chips are produced and controlled the surface roughness also [7, 8]. Whereas delamination and burr measurements were carried through optical microscopic and digital photography. Delamination was measured the adjacent surface of the actual drilled hole, however delamination zone were identify from the actual drill diameter [9]. In addition the quality assessments were controlling and investigated the fiber fraying and hole size in drilled CFRP/Ti stacking FML. Feed rate will be influencing the fiber fraying in drilling. Then the main parameters is tolerance maintain in the hole. Because, dissimilar material having various elastic modulus and different thermal expansion in hole [10].

\section{EXPERIMENTAL WORK}

\section{A. Fabrication of Laminates}

Fiber metal laminates were fabricated using glass fiber/epoxy with aluminum 7475 (GLARE) face sheet. Fig. 1 shows the stacking 
sequence of GLARE (3/2) produced in this study,

Consists of alternative stacking of both thin three aluminum sheets $(0.4 \mathrm{~mm})$ with two glass/epoxy $(0.25-0.5$ $\mathrm{mm})$. Sandwich $(\mathrm{Al} / \mathrm{Gl} / \mathrm{Al} / \mathrm{Gl} / \mathrm{Al})$ are built by layup in a vacuum bag mold and then cured in an autoclave cycle with high pressure ( 6 bar) and cure temperature of $120^{\circ} \mathrm{C}$. molded composites then cut into the required size for various test dimensions as required by respective standards.

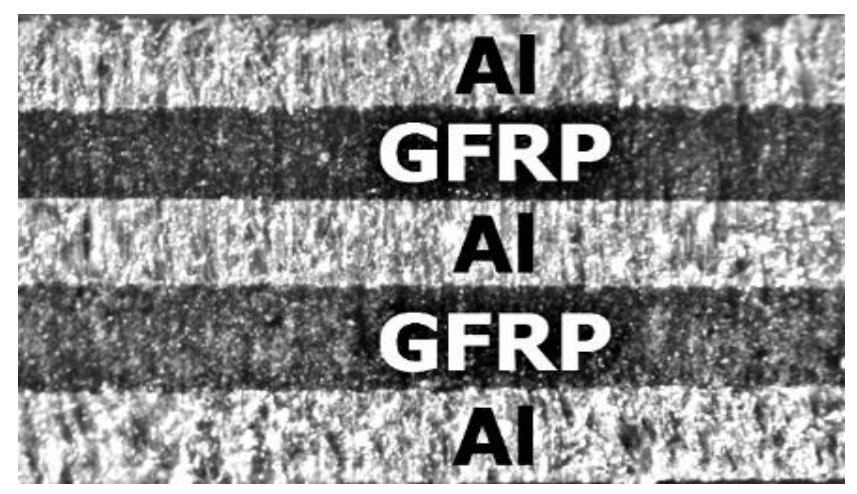

Fig. 1. Stacking sequence of GLARE (3/2) produced

\section{B. Drilling of Laminates}

Drilling on the produced laminates were done using a CNC drilling (HYTECH, China) with the Longitude travels $250 \mathrm{~mm}$, cross travels $150 \mathrm{~mm}$, vertical travels $200 \mathrm{~mm}$, spindle speed range 200-2500rpm, motor-DC motor 1.5 HP, clamping area $450 * 160 \mathrm{~mm}$. Drilling was done with two different drill bits of various geometry. Table I shows the specification of drill bits used in this study (Shown Fig. 2). Drilling on the laminates were made at an interval of $20 \mathrm{~mm}$ center to center.

Table I: Nomenclature difference of drill bits used in this

\begin{tabular}{lcc}
\multicolumn{3}{c}{ study } \\
\hline \multicolumn{1}{c}{ Parameters } & $\begin{array}{c}\text { Drill-1 } \\
\text { as D1 }\end{array}$ & $\begin{array}{c}\text { Drill-2 } \\
\text { as D2 }\end{array}$ \\
\hline Materials & HSS & HSS \\
No of Flute & 2 & 3 \\
Faced & 2 & 6 \\
Diameter $(\mathrm{mm})$ & 6 & 6 \\
Point angle $\left(^{0}\right)$ & 120 & 150 \\
Helix angle $\left(^{0}\right)$ & 30 & 25 \\
Clearance angle $\left(^{0}\right)$ & 8 & 7 \\
Rake angle $\left(^{0}\right)$ & 30 & 10 \\
\hline
\end{tabular}

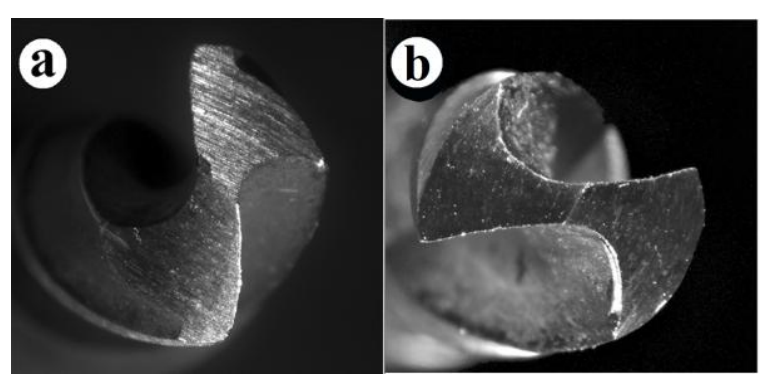

Fig. 2. Drill bit geometries used D1 (a), D2 (b)

\section{Hole quality analysis}

In the beginning quality assessment of hole were done with cutting edge rounding (CER) and burr realization. The CER and burr be influenced by the different drill bit geometry like spiral of flute, point angle, helix angle, lip angle and also feed rate is $0.05 \mathrm{~mm} / \mathrm{rev}$ and spindle speed is $2000 \mathrm{rpm}$ respectively. Four drills per each drill tool were done on the fabricated laminates. Exploring of the cutting edge rounding and burr topographic of the machined GLARE were done at trinocular microscope (OM) (Motic, Korea). In addition, fiber fraying (uncut fibers available in the machined portion) is also done for the drilled holes. Protrusion made on the top and bottom edges are also considered as a quality factor.

\section{Diametrical measurement}

From the quality aspects, additional parameter to analyze the drilling of GLARE is "Diametrical". The circular dimensional tolerances were measured with $\mathrm{OM}$ and compared with CMM measurements (not reported here).

\section{MATH}

\section{A. Drilling quality analysis}

Fig. 2 illustrate the effect of drill bit geometry (D1 \& D2) on the hole edge quality of drilling GALRE (3/2). Hole edge quality is primarily controlled by number of flutes in drill bit and feed rate as well [8]. Fig. 3a shows the drill in surface (top) of laminate. The circular edge is appeared with distortion on its periphery (marked in the Fig. 3a.). Due to less cutting point compare to the three flute drill bit, the metal removal is lower in D1. Hence, such edge distortions occurred. While drilling-in period, second and third Al ply were drawn out as chips (continuous-Fig. 5a).

Due to the ductility of aluminum, at drill-out zone, edge distortions are high around the circular edges (Fig. 3b). Since the effective flute area is more in the two flute drill bit (D1), less burr of bottom $\mathrm{Al}$ layer is found. Regarding the intermediate glass fibers/epoxy, the polymer system was not completely machined since there are less contact points (D1) to remove the high stiff fiber materials. Presence of massive fibrous materials inside the drilled hole attributes the slipping of glass fibers into the drill bit flutes and insufficient machining process. The slipped fibers were appeared with oriented in the direction of the drill bit rotation which again confirm the slipping of the glass fiber through the drill bit flutes.
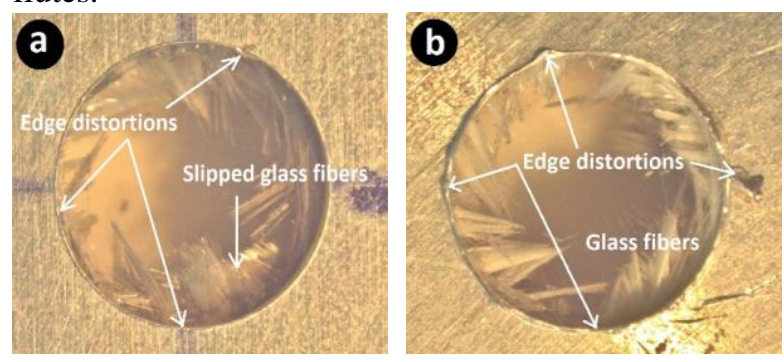

Fig. 3. Hole produced using D1 drill (two flute) (a) drill-in top ply, (b) drill-out bottom ply

Fig. 4 shows the hole quality of the drill made with three flute drill bit (D2). During the drill-in from top al ply, due to the more number of cutting points, removal of surface materials is complete and hence no circular edge distortions were noted. Fig. 4a evidence the distortion free circular edge. On the other hand, less 
flute path way area severely affects the drill-out bottom al area. Fig. 4b attribute the poor removal of bottom al layer.

The edge in Fig. $3 b$ appeared with massive edge distortions around it. Meantime, glass fibers are effectively machined when compared with the D1 hole (Fig. 3a,b). Most of the intermediate fibers were machined to produce clear circular hole.
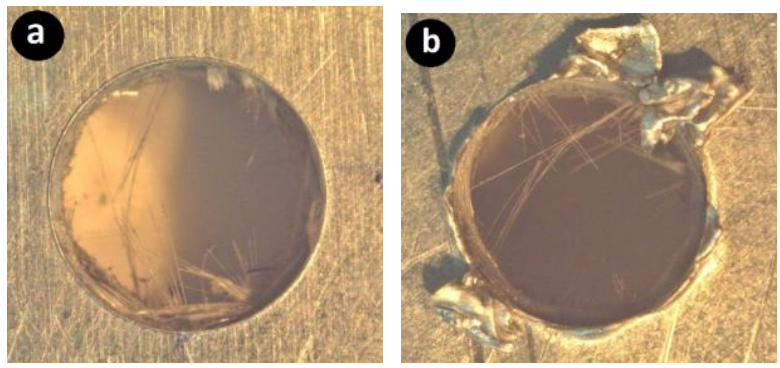

Fig. 4. Hole produced using D2 drill (three flute) (a) drill-in top ply, (b) drill-out bottom ply

\section{B. Chip analysis}

Fig. 5 shows the chip shape and size resulted from drilling with different drill bit geometry with the feed rate of 0.05 $\mathrm{mm} / \mathrm{rev}$ at spindle speed $2000 \mathrm{rpm}$. Chips were collected after the drilling of each experiments. Fig. 5a shows the chips produced from the drilling done with D1 drill bit (two flute). Chips found continuous and spiral. Geometry of such chips attributes the ductility of aluminum. Meantime During the drilling less glass fiber cut-outs were collected. The slip nature of the glass fiber (due to polished fiber surface) most of the fibers become uncut while they passed through the flutes.

In addition, fiber debris are so short which attribute localized machining of the fiber-polymer composites. Long $\mathrm{Al}$ chips were found only during the drill-out period. Fig. 5b shows the chips produced during the drilling done with D2 tool. One can see the short chips which attributes the moderate drilling process which in-turn less distorted hole edges. Drilling with D2 tool produced chips of $0.07 \mathrm{~mm}$ wide whereas the D1 produced $0.12 \mathrm{~mm}$ wider. Chips width are directly influenced by the flute width. Due to the multiple number of drill cuts offered by the D2 than D1 could be reason for the improved edge quality. Feed rate are also controls the chip size, $0.1 \mathrm{~mm} / \mathrm{rev}$ was critical parameter of chip breaking level [3].
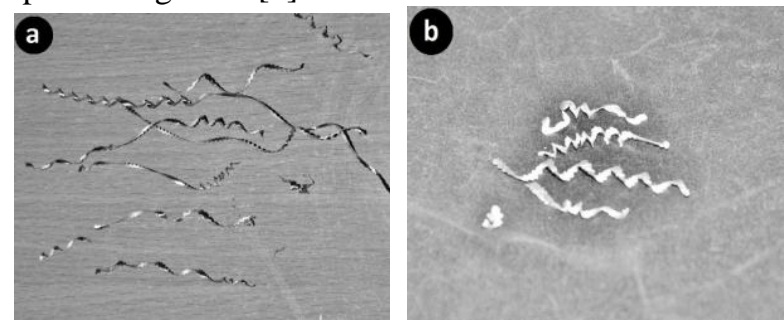

Fig. 5. Chips produced during the drilling of FML (a) drilled with D1 tool, (b) drilled with D2 tool.

\section{Circularity analysis}

The effect of drill bit geometry on the hole size when drilling the GLARE (3/2) using D1 and D2 drill tools are shown in figure 5. Machining of FML using D1 offers closer tolerance with the drill tool diameter to the produced hole (Fig. 6a). In addition, feed rate also a controlling factor to achieve good tolerances. Lower the feed results good dimensional tolerance [11]. Especially in the case of stacking dissimilar materials (Al and Fiber composite) feed rate should be as minimum as possible to achieve complete drill of entire mass. GLARE response will be different from other heterogeneous materials, since the elastic modulus and thermal expansion coefficient of the stacked materials are too much heterogeneous to each other. At this point, the removal tool geometry played a vital role to produce good quality holes. Fig. 6b shows the hole geometry produced using D2 tool. Higher deviations noted from D1 drill. Since three flute drill tool has larger contact points which results higher thermal expansion in-turn poor dimensional tolerance. Meantime, since the polymer composite has lesser expansion than the $\mathrm{Al}$, projected internal structures were noted in the drill hole.
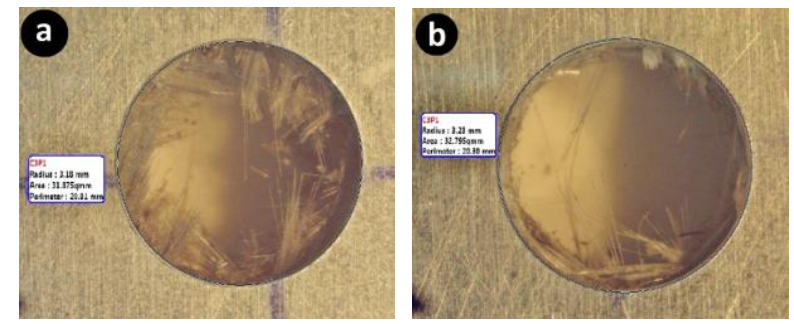

Fig. 6. Drilled hole geometry, (a) hole drilled with D1 drill tool, (b) drilled with D2 drill tool.

\section{CONCLUSION}

Drilling of the GLARE (3/2) laminates with various drill bit (D1 \& D2) geometries were done, the following are some conclusion derived from the experimental results.

- Drilling qualities were analyzed in-terms of fiber fraying and circularity error.

- At constant feed rate of $0.05 \mathrm{~mm} / \mathrm{rev}$, drilling with D1 tool create greater edge qualities than the drill made with D2 tool.

- On the other hand D2 (three flute) tool massively removes the inter-laminar glass fibers and produced more appropriate cylinder inside the drilled volume.

- Drill-out side (bottom) edge quality was very poor in D2 tool drill and finer for D1 tool drill.

\section{REFERENCES}

1. D. F. Liu, Y. J. Tang, W.L. Cong, A review of mechanical drilling for composite laminates, Composite Structures, Vol.94, pp.1265-1279, 2012.

2. A. Velayudham, R. Krishnamurthy, T. Soundarapandian, Evaluation of drilling characteristics of high volume fraction fiber glass reinforced polymeric composites. Int J Mach Tools Manufact Vol.5, pp.339-406, 2005

3. R. Zitoune, V. Krishnaraj, F. Collombet, Study of drilling of composite material and aluminium stack, Composite Structures, Vol.92, pp.1246-1255, 2010.

4. M. SenthilKumar, A. Prabukarthi, V. Krishnaraj, Study on Tool Wear and Chip Formation during Drilling Carbon Fiber Reinforced Polymer (CFRP)/ Titanium Alloy (Ti6Al4V) Stacks, Procedia Engineering, Vol.64, pp.582 - 592, 2013

5. X. Wang, P. Y. Kwon, C Sturtevant, D. Kim, J. Lantrip, Comparative tool wear study based on drilling experiments on CFRp/ti stack and its individual 
layers, International journal of Wear, http://dx.doi.org/10.1016/j.wear.2014.05.007

6. A. Faraz, D. Biermann, K. Weinert, Cutting edge rounding: An innovative tool wear criterion in drilling CFRP composite laminates, International Journal of Machine Tools \& Manufacture, Vol.49, pp.1185-1196, 2009.

7. M. Thirukumaran, JT. Winowlin Jappes, I. Siva, S.C. Amico, J. Paulo Davim, Invesigation of Margin Effect to Minimize Delamination during Drilling of Differently Stacked GFRP-Aluminum Fiber Metal Laminates (3/2 GLARE), Journal of Manufacturing Technology Research, Vol.10 no.1-2, pp. 18-27, 2018.

8. O. A. Pawar, Y. S. Gaikhe, A. Tewari, R. Sundaram, S. S. Joshi, Analysis of hole quality in drilling GLARE fiber metal laminates, Composite Structures, Vol.123, pp.350-365, 2015.

9. O. Isbilir and E. Ghassemieh, Comparative study of tool life and hole quality in drilling of CFRP/Titanium stack using coated carbide drill, Machining Science and Technology, Vol.17, no.3, pp.380-409, 2013.

10. S. Alizadeh Ashrafi, S. Sharif, A. Akhavan Farid, M.Y. Yahya, Performance evaluation of carbide tools in drilling CFRP-Al stacks, Journal of Composite Materials, Vol.48, no.17, pp.2071-2084, 2014.

11. C.L. Kuoa, S.L. Soo, D.K. Aspinwall, W. Thomas, S. Bradley, D. Pearson, R. M'Saoubi, W. Leahy, The effect of cutting speed and feed rate on hole surface integrity in single-shot drilling of metallic-composite stacks, Procedia CIRP, Vol.13, pp.405 - 410, 2014.

\section{AUTHORS PROFILE}

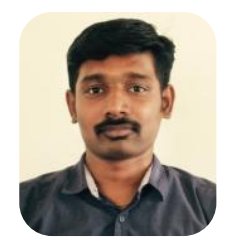

Mr. Thirukumaran M is working as Assistant Professor in the Department of Mechanical and Automation Engineering, PSN College of Engineering and Technology, Tirunelveli, Tamilnadu, India. He has a graduate in Mechanical Engineering from Kalasalingam University, in 2013. He received his Master degree in Manufacturing Engineering from Anna University, Chennai, Tamil Nadu, India, in 2015. He is doing Ph.D in the Department of Mechanical Engineering, Kalasalingam Academy of Research and Education, Krishnan Koil, Tamil Nadu, India. His research area: hybrid laminate structure and polymer composite.

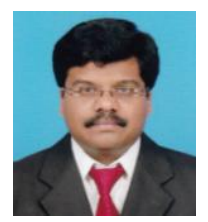

Dr. Winowlin Jappes J T graduated in 1997 from Manonmaniam Sunderanar University, India in Mechanical Engineering. In 1999, he has completed his masters in Production Engineering from Annamalai University. He completed his Ph.D degree in 2004 in the area of Composite Deposition at Indian Institute of Technology Madras, Chennai. He has completed three DST funded research projects and published more than 125 research articles which include 65 International Journal papers. Currently, he is working as Senior Professor in Kalasalingam University, India. His research interest includes high performance composite materials, machining of hard materials, optimization techniques, etc. At present, he is working as Professor and Dean, School of Automotive and Mechanical Engineering, Kalasalingam Academy of Research and Education, India.

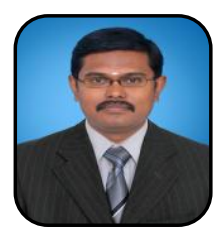

Dr. Siva I is obtained his Bachelors Degree in Mechanical Engineering in Mechanical Engineering from the Manonmaniam Sundaranar University, Tamilnadu/India (2002). In 2005 he acquired a Master's degree in Manufacturing Engineering by the Anna University, Tamilnadu/India and completed his $\mathrm{PhD}$ by the Department of Mechanical Engineering Kalasalingam University/India (2012). He is currently a Visiting Researcher at the Federal University of Rio Grande do Sul/Brazil in the Department of Materials Engineering. He is leading an Indo-Brazil Centre for Composite Materials in Kalasalingam University/India. His area of expertise is Engineering Materials with the focus on processing natural fibers, bio-composite, fiber surface modification, interfacial analysis, wear and vibrational analysis of natural fiber composites. He received a BJT-B fellowship from $\mathrm{CNPq} / \mathrm{Brazil}$. Recently, he received a collaboration project between India and Brazil through DST/India and CNPq/Brazil. 